\title{
Study on Temporal and Spatial Evolution Characteristics of Air Quality in Urban Agglomerations in Northwestern China
}

\author{
Gao Wenqi ${ }^{1}$, Wu Shouxia ${ }^{2, *}$, Li Ying ${ }^{2}$, Zhang Weifeng ${ }^{1}$ \\ ${ }^{1}$ School of Civil Engineering, Lanzhou Institute of Technology, Lanzhou, Gansu, China \\ ${ }^{2}$ School of Electronic Information Engineering, Lanzhou Institute of Technology, Lanzhou, Gansu, China
}

\begin{abstract}
This paper analyzes the air quality monitoring data of Qingyang, Tianshui and Pingliang in northwestern China in 2015 by time series analysis. The research results are as follows: (1) the concentrations of $\mathrm{PM}_{2.5}, \mathrm{PM}_{10}$ and $\mathrm{SO}_{2}$ in the three cities began to decline in March, reached a minimum in September before rising gradually; (2) concentrations of $\mathrm{PM}_{2.5}, \mathrm{PM}_{10}$ and $\mathrm{SO}_{2}$ in the three cities were low in summer and autumn, but high in winter and spring; (3) the coefficient of correlation among $\mathrm{PM}_{2.5}, \mathrm{PM}_{10}$ and $\mathrm{SO}_{2}$ in the three cities was greater than 0.589, indicating a strong correlation.
\end{abstract}

\section{Introduction}

China has experienced rapid industrialization and urbanization with the development of technology and economy since the reform and opening-up. The advancement of industrialization and urbanization is accompanied by huge consumption of resources and severe damages to the environment. The extensive development model with high energy consumption and low efficiency has further aggravated the destruction of the ecological environment and caused a series of environmental problems ${ }^{[1]}$. Air pollution will not only cause serious economic losses ${ }^{[2]}$, but also reduce atmospheric visibility ${ }^{[3]}$. The particulate matter in the air can induce respiratory diseases ${ }^{[4]}$ and cardiovascular and cerebrovascular diseases ${ }^{[5]}$, having a significant impact on human health. According to statistics, about 6.1 million people died of air pollution-related diseases ${ }^{[6]}$ in 2016.

The monitoring and characteristic analysis of air quality have become the current research hotspots of Chinese and foreign scholars in recent years. Mu et al. ${ }^{[7]}$ studied a nationwide large-scale smog incident in China in January 2013 and estimated that the incident caused about RMB 23 billion direct economic losses to traffic and health based on the publicly reported data. Liao et al. ${ }^{[8]}$ studied the variation trend of air pollutant concentration in Shenzhen from 2006 to 2016. The results showed that concentrations of $\mathrm{SO}_{2}, \mathrm{PM}_{10}$ and $\mathrm{NO}_{2}$ in Shenzhen presented an overall downward trend from 2006 to 2016 and that the air quality had improved significantly year by year but there was still a big gap from air quality standards of developed countries. Existing studies mostly focus on municipalities directly under the central government such as Beijing, Shanghai and Tianjin and capital cities in central and eastern China. Related studies in northwestern China also focus on provincial capital cities. The overall research on the air quality in small underdeveloped urban agglomerations has not been reported yet.

Qingyang, Pingliang and Tianshui are located in northwestern China, the climate is the warm temperate zone, continental monsoon climate. This study analyzes and evaluates the air quality status of the three cities in 2015 and analyzes the correlation of cities and pollutants with the multiple regression method with a view to provide data support for air pollution prevention and control decision-making and comprehensive crossregional management in third- and fourth-tier cities in under-developed regions in northwestern China.

\section{Data and method}

\subsection{Data source}

The air quality data of Qingyang, Pingliang and Tianshui in 2015 came from the China Air Quality Online Monitoring and Analysis Platform (https://www.aqistudy.cn/). The air quality monitoring data included average concentrations of $\mathrm{PM}_{2.5}, \mathrm{PM}_{10}, \mathrm{SO}_{2}$, $\mathrm{CO}, \mathrm{NO}_{2}$ and $\mathrm{O}_{3}$, etc.

\subsection{Evaluation criteria}

The evaluation criteria used in this study are from the Ambient Air Quality Standard (BG3095-2012) ${ }^{[9]}$.

\subsection{Research method}

The analysis was mainly conducted with the time series analysis method and the multiple regression method in statistics, and the data was processed preliminarily based on Excel 2007. The variation trend of $\mathrm{PM}_{2.5}, \mathrm{PM}_{10}, \mathrm{SO}_{2}$,

\footnotetext{
* Corresponding author: ${ }^{\mathrm{a}}$ wushouxia@126.com
} 
$\mathrm{NO}_{2}$ and $\mathrm{O}_{3}$ concentrations in each city was analyzed with the software Origin, and the correlation of pollutants and cities with the software SPSS. Seasons were divided by the combination of astronomical seasons and climatic seasons.

\section{3 results and analysis}

\subsection{Variation characteristics of monthly average}

\section{mass concentrations of pollutants}

Figure 1 shows variation curves of the monthly average $\mathrm{PM}_{2.5}$ data of the three cities in Gansu Province in 2015. According to the figure, the $\mathrm{PM}_{2.5}$ concentration in all the three cities was low in the middle and high on both sides, and had a small peak in July. The $\mathrm{PM}_{2.5}$ concentration in Pingliang was slightly higher than that in the other two cities, with a maximum of $83 \mu \mathrm{g} / \mathrm{m}^{3}$ and a minimum of 24 $\mu \mathrm{g} / \mathrm{m}^{3}$.

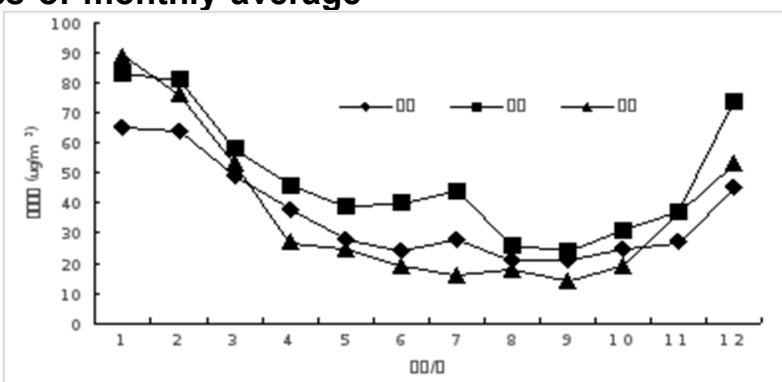

Figure 1. Variation curves of the monthly average mass concentrations of $\mathrm{PM}_{2.5}$ in the three cities in 2015

Figure 2 shows variation curves of the monthly average $\mathrm{PM}_{10}$ data of the three cities in Gansu Province in 2015. According to the figure, the $\mathrm{PM}_{10}$ concentration in
Pingliang was the highest among the three cities, with a maximum of $149 \mu \mathrm{g} / \mathrm{m}^{3}$ and a minimum of $49 \mu \mathrm{g} / \mathrm{m}^{3}$.

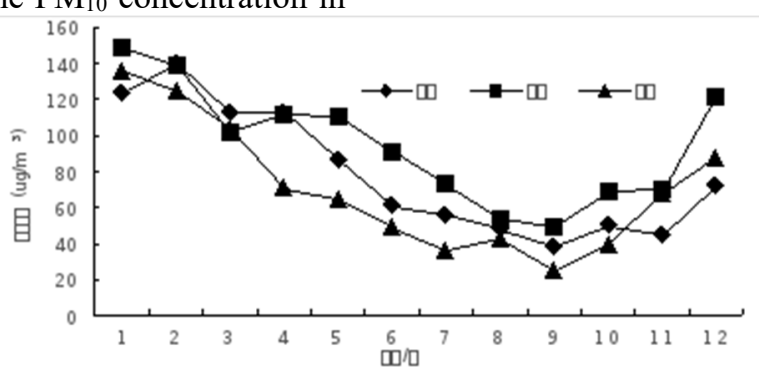

Figure 2. Variation curves of the monthly average mass concentrations of $\mathrm{PM}_{10}$ in the three cities in 2015

Figure 3 shows variation curves of the monthly average $\mathrm{SO}_{2}$ data of the three cities in 2015 . According to the figure, the variation curves of $\mathrm{SO}_{2}$ concentrations in the three cities were all U-shaped; the $\mathrm{SO}_{2}$ concentrations were low and well consistent, ranging from 5 to $16 \mu \mathrm{g} / \mathrm{m}^{3}$ from April to October, and increased significantly in other months. From November to March, the $\mathrm{SO}_{2}$ concentration in Pingliang was the lowest among the three cities, ranging from 27 to $45 \mu \mathrm{g} / \mathrm{m}^{3}$.

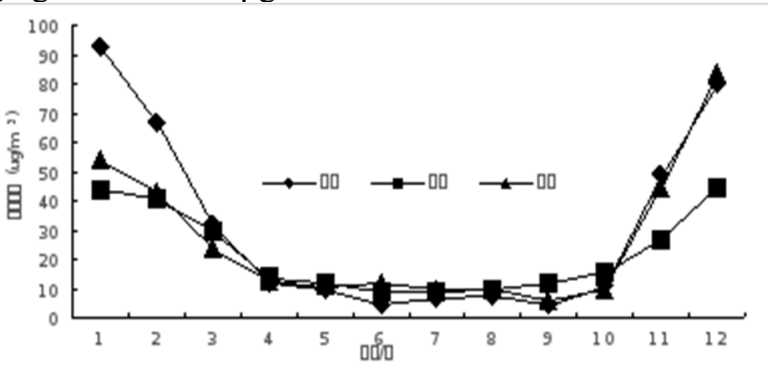

Figure 3. Variation curves of the monthly average mass concentrations of $\mathrm{SO}_{2}$ in the three cities in 2015

Figure 4 shows variation curves of the monthly average $\mathrm{NO}_{2}$ data of the three cities in Gansu Province in 2015. The annual average concentrations of $\mathrm{NO}_{2}$ in Qingyang, Pingliang and Tianshui were 20.42, 44.33, and $33.8 \mu \mathrm{g} / \mathrm{m}^{3}$ respectively. $\mathrm{NO}_{2}$ concentrations in Pingliang and Qingyang had small variations, but the concentration in Pingliang was much higher than that in Qingyang. The concentration of $\mathrm{NO}_{2}$ in Qingyang was the lowest, ranging from 12 to $95 \mu \mathrm{g} / \mathrm{m}^{3}$. That in Tianshui had the greatest variation. 


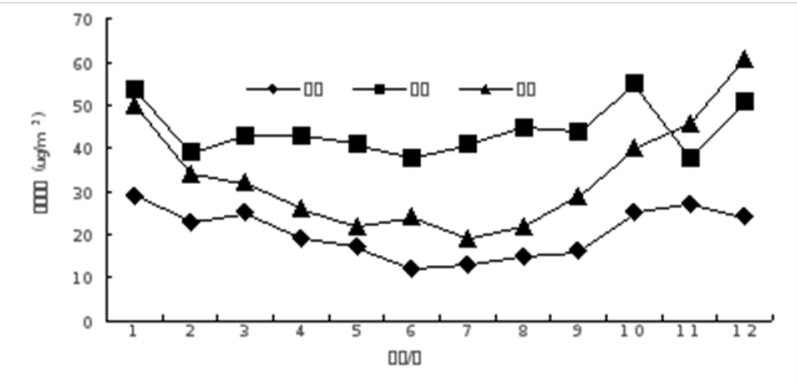

Figure 4. Variation curves of the monthly average mass concentrations of $\mathrm{NO}_{2}$ in the three cities in 2015

Figure 5 shows variation curves of the monthly average mass concentrations of $\mathrm{O}_{3}$ in the three cities in eastern Gansu Province in 2015. Variation curves of $\mathrm{O}_{3}$ were completely different from those of other pollutants, showing an inverted "U" shape. The $\mathrm{O}_{3}$ concentrations in the cities were the lowest in November, ranging from 37 to $38 \mu \mathrm{g} / \mathrm{m}^{3}$, and high from April to July. The highest $\mathrm{O}_{3}$ concentration in Qingyang was $134 \mu \mathrm{g} / \mathrm{m}^{3}$.

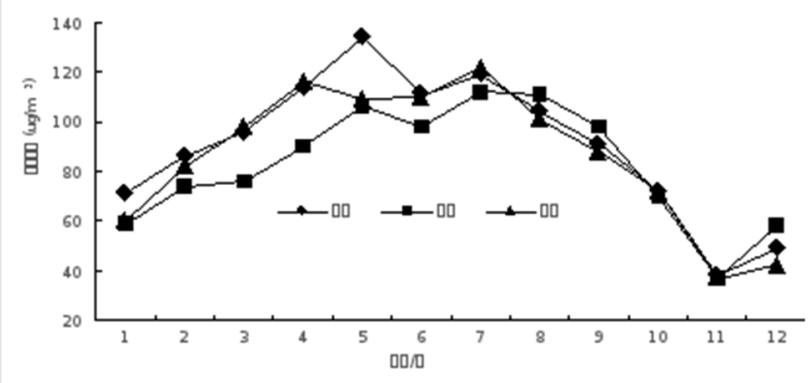

Figure 5. Variation curves of the monthly average mass concentrations of $\mathrm{O}_{3}$ in the three cities in 2015

In summary, the concentrations of $\mathrm{PM}_{2.5}, \mathrm{PM}_{10}$ and $\mathrm{SO}_{2}$ in the three cities in eastern Gansu showed a downward trend from March, fell to the lowest level in September and then increased gradually, among which the $\mathrm{SO}_{2}$ concentration remained at a low level from April to October and increased sharply thereafter. The $\mathrm{NO}_{2}$ concentrations in the three cities were slightly higher in November and December. The variation of their $\mathrm{O}_{3}$ concentrations was different from that of other pollutants, showing an inverted "U" shape.

\subsection{Correlations between air pollutants in different cities}

Correlation analysis refers to the analysis of two or more related variable elements to measure their correlation.

Table 1 shows the results of Spearman correlation analysis of different pollutants in the same city for the three cities in 2015.

Table 1. Spearman correlation coefficients of pollutants in the three cities in 2015

\begin{tabular}{|c|c|c|c|c|c|c|}
\hline City & Pollutants & $\mathrm{PM}_{2.5}$ & $\mathrm{PM}_{10}$ & $\mathrm{SO}_{2}$ & $\mathrm{NO}_{2}$ & $\mathrm{O}_{3}$ \\
\hline \multirow{5}{*}{$\begin{array}{c}\text { Qingya } \\
\text { ng }\end{array}$} & $\mathrm{PM}_{2.5}$ & 1 & & & & \\
\hline & $\mathrm{PM}_{10}$ & $.882^{* *}$ & 1 & & & \\
\hline & $\mathrm{SO}_{2}$ & $.814^{* *}$ & $.589^{*}$ & 1 & & \\
\hline & $\mathrm{NO}_{2}$ & .569 & .289 & $.839^{* *}$ & 1 & \\
\hline & $\mathrm{O}_{3}$ & -.207 & .102 & $-.648^{*}$ & $-.739^{* *}$ & 1 \\
\hline \multirow{5}{*}{$\begin{array}{c}\text { Pinglia } \\
\text { ng }\end{array}$} & $\mathrm{PM}_{2.5}$ & 1 & & & & \\
\hline & $\mathrm{PM}_{10}$ & $.937^{* *}$ & 1 & & & \\
\hline & $\mathrm{SO}_{2}$ & $.628^{*}$ & $.618^{*}$ & 1 & & \\
\hline & $\mathrm{NO}_{2}$ & -.004 & -.018 & .351 & 1 & \\
\hline & $\mathrm{O}_{3}$ & -.396 & -.389 & $-.844^{* *}$ & -.192 & 1 \\
\hline \multirow{5}{*}{$\begin{array}{c}\text { Tiansh } \\
\text { ui }\end{array}$} & $\mathrm{PM}_{2.5}$ & 1 & & & & \\
\hline & $\mathrm{PM}_{10}$ & $.979^{* *}$ & 1 & & & \\
\hline & $\mathrm{SO}_{2}$ & $.915^{* *}$ & $.887^{* *}$ & 1 & & \\
\hline & $\mathrm{NO}_{2}$ & $.685^{*}$ & .567 & $.713^{* *}$ & 1 & \\
\hline & $\mathrm{O}_{3}$ & -.523 & -.385 & -.556 & $-.907^{* *}$ & 1 \\
\hline
\end{tabular}

${ }^{* *}$. At the level of 0.01 (two-tailed), indicating significant correlation. ${ }^{*}$. At the level of 0.05 (two-tailed), indicating significant correlation.

Table 1 indicates a strong positive correlation among $\mathrm{PM}_{2.5}, \mathrm{PM}_{10}$ and $\mathrm{SO}_{2}$ in the three cities with a coefficient of correlation between 0.589 and 0.979 , a positive correlation between $\mathrm{NO}_{2}$ and $\mathrm{PM}_{2.5}, \mathrm{PM}_{10}$ and $\mathrm{SO}_{2}$ in
Qingyang and Pingliang and a negative correlation between the same in Pingliang, and a strong negative correlation between $\mathrm{O}_{3}$ and $\mathrm{NO}_{2}$ in Qingyang and Tianshui. The reason is that $\mathrm{O}_{3}$ in the air near the ground in urban 
areas is generated by a series of photochemical reactions of its precursor $\mathrm{NOx}^{[10]}$ :

$$
\begin{array}{r}
\mathrm{NO}_{2}+\mathrm{hv} \rightarrow \mathrm{NO}+\mathrm{O} \\
\mathrm{O}_{2}+\mathrm{O} \rightarrow \mathrm{O}_{3} \\
\mathrm{O}_{3}+\mathrm{NO} \rightarrow \mathrm{N}_{2}+\mathrm{O}_{2}
\end{array}
$$

In the real environment, the more oxidizing free radical present will react with $\mathrm{NO}$, leading to the termination of the zero-cycle reaction in formulas 1 to 3 and thereby the accumulation of $\mathrm{O}_{3}$ concentration ${ }^{[25]}$ as shown in formulas (4) and (5).

$$
\begin{array}{r}
\mathrm{OH}+\mathrm{VOC}_{\mathrm{s}} \rightarrow \mathrm{RO}_{2}+\mathrm{CH}_{2} \mathrm{O} \\
\mathrm{O}_{2}+\mathrm{NO} \rightarrow \mathrm{NO}_{2}+\mathrm{PAN}
\end{array}
$$

The reactions above show that the most fundamental cause of $\mathrm{O}_{3}$ generation is the photolysis of $\mathrm{NO}_{2}$. Therefore, $\mathrm{NO}_{2}$, as one of the precursors of $\mathrm{O}_{3}$, shows a good negative correlation with the concentration. However, $\mathrm{O}_{3}$ and $\mathrm{NO}_{2}$ had a weak correlation in Pingliang due to the high level of the $\mathrm{NO}_{2}$ concentration throughout the year in combination with the influence of volatile organic compounds (VOCS) and other pollutants produced by the chemical industry and other industries ${ }^{[11]}$.

Table 2 shows the results of further analysis of the Spearman correlation of the same pollutant among different cities. Except for the correlation coefficients of $\mathrm{NO}_{2}$ between Pingliang and Qingyang and between Pingliang and Tianshui, the others were close to or greater than 0.8 , indicating a strong correlation. According to Figure 5, the $\mathrm{NO}_{2}$ concentration in Pingliang remained at a high level throughout the year, resulting in the correlation coefficients of $\mathrm{NO}_{2}$ between Qingyang and Pingliang and between Pingliang and Tianshui ranging from 0.3 to 0.4 . Studies have shown that the contribution rate of motor vehicles to $\mathrm{NO}_{2}$ is about $60 \%{ }^{[12]}$. Pingliang as an important coal-producing area in Gansu Province, it had an annual output of raw coal of 21.3556 million tons in 2015 . Except for mining and processing, the tail gas emission caused by the transportation of a large amount of raw coal was much higher compared to the other two cities, which is also an important reason for this phenomenon.

Table 2. Spearman correlation coefficient of the same pollutant among different cities in 2015

\begin{tabular}{ccccc}
\hline Pollutants & City & Qingyang & Pingliang & Tianshui \\
\hline \multirow{3}{*}{$\mathrm{PM}_{2.5}$} & Qingyang & 1 & & \\
& Pingliang & $.944^{* *}$ & 1 & \\
& Tianshui & $.873^{* *}$ & $.828^{* *}$ & 1 \\
\hline \multirow{5}{*}{$\mathrm{PM}_{10}$} & Qingyang & 1 & & \\
& Pingliang & $.918^{* *}$ & 1 & \\
& Tianshui & $.827^{* *}$ & $.867^{* *}$ & 1 \\
\hline \multirow{5}{*}{$\mathrm{SO}_{2}$} & Qingyang & 1 & & \\
& Pingliang & $.935^{* *}$ & 1 & \\
& Tianshui & $.878^{* *}$ & $.795^{* *}$ & 1 \\
\hline \multirow{3}{*}{$\mathrm{NO}_{2}$} & Qingyang & 1 & & \\
& Pingliang & .347 & 1 & \\
& Tianshui & $.835^{* *}$ & .361 & 1 \\
\hline \multirow{2}{*}{$\mathrm{O}_{3}$} & Qingyang & 1 & & \\
& Pingliang & $.886^{* *}$ & 1 & \\
& Tianshui & $.958^{* *}$ & $.869^{* *}$ & 1
\end{tabular}

${ }^{* *}$.At the level of 0.01 (two-tailed), indicating significant correlation.

\section{Discussion}

\subsection{Time series analysis of air quality}

$\mathrm{PM}_{2.5}$ and $\mathrm{PM}_{10}$ concentrations in all the three cities were low in summer and autumn and high in winter and spring. The concentration of $\mathrm{SO}_{2}$ showed a typical "U" shape, remained at a low level from April to October and increased significantly in other months. That of $\mathrm{O}_{3}$ showed an inverted "U" shape with the characteristic of being "high in spring and summer and low in autumn and winter". This agrees with the research results of Wang et al. ${ }^{[13]}$ on urban air quality in the Fenwei Plain. These variation characteristics are related to the combined effect of pollutant emissions, meteorological conditions, and photochemical reactions. In summer, there are fewer combustion sources and pollution emissions, strong vertical diffusion of the atmosphere, more precipitation and strong scavenging action, which can lower the concentration of pollutants. A large amount of pollutants from central heating and the emission of fossil fuel combustion coupled with unfavorable diffusion conditions during the heating period in winter (mid-November to mid-March of the following year) in comparison with other seasons result in a high concentration of pollutants . $\mathrm{NO}_{2}$ mainly comes from automobile exhaust, power plants and industrial activities, among which automobile exhaust is the main emission source ${ }^{[14]}$. Huating Coal Field in Pingliang is the largest coalfield in Gansu Province. The transportation and deep processing of coal produce a large amount of $\mathrm{NO} 2$, resulting in a high $\mathrm{NO}_{2}$ concentration throughout the year in Pingliang.

\subsection{Correlation analysis and reasons}

There was a strong positive correlation among $\mathrm{PM}_{2.5}$, $\mathrm{PM}_{10}$ and $\mathrm{SO}_{2}$ in the three cities, with a correlation coefficient between 0.589 and 0.979 . Their main pollutants were all particulate matter, which was the same as in other parts of China and was consistent with the research results of scholars such as Sun ${ }^{[15]}$ on northern cities. As a coal resource-based city, Pingliang was faced with a large amount of $\mathrm{NO}_{2}$ from the mining, processing and transportation of raw coal.

According to the analysis of the correlation among 
different cities for the same pollutant, the other coefficients were close to or greater than 0.8 , indicating a strong correlation, except for the correlation coefficient of $\mathrm{NO}_{2}$ between Pingliang and Qingyang and between Pingliang and Tianshui. The three cities, all located in Gansu Province in northwestern China, have similar geographical environment and climate, city scale and level of social and economic development which result in their strong correlation.

\subsection{Advantages and limitations}

This paper studies the characteristics and correlation of air quality, monthly average mass concentrations of pollutants and AQI in small urban agglomerations in northwestern China, explores their underlying variation features and regional synergic relationship and discusses the variation mechanism. In addition, it conducts a multiscale analysis on the evolution of each pollutant in time series and provides more research results.

However, it only analyzes the evolution characteristics of the three cities in 2015 and lacks research on large-scale evolution rules. Moreover, urban air quality is also affected by meteorological factors, population, economic development and other factors, which will be studied in future work.

\section{Conclusion}

In summary, this paper makes the following conclusions:

1) The concentrations of $\mathrm{PM}_{2.5}, \mathrm{PM}_{10}$ and $\mathrm{SO}_{2}$ in the three cities showed a downward trend from March, fell to the lowest level in September and then increased gradually, among which the $\mathrm{SO}_{2}$ concentration remained at a low level from April to October and increased sharply thereafter. The $\mathrm{NO}_{2}$ concentration in Pingliang was 2.17 times that of Qingyang and 1.31 times that of Tianshui. The variation of their $\mathrm{O}_{3}$ concentrations was different from that of other pollutants, showing an inverted "U" shape.

2) In the three cities, particulate matter had a higher over-limit ratio. The over-limit ratio of $\mathrm{PM}_{10}$ in Qingyang was slightly higher than that of $\mathrm{PM}_{2.5}$, and the ratio of fine particulate matter in Pingliang and Tianshui was higher than that of coarse particulate matter. $\mathrm{SO}_{2}$ and $\mathrm{NO}_{2}$ concentrations had a low over-limit ratio and exceeded the standard only in a few months of the year. The concentration of $\mathrm{O}_{3}$ did not exceed the standard.

3) According to the analysis of the Spearman correlation among different pollutants in the three cities, the correlation coefficient of $\mathrm{PM}_{2.5}, \mathrm{PM}_{10}$ and $\mathrm{SO}_{2}$ was between 0.589 and 0.979 , indicating a strong correlation. According to the analysis of the Spearman correlation among different cities for the same pollutant, the other correlation coefficients except for $\mathrm{NO}_{2}$ were all high.

These findings can help in better understanding the evolution characteristics of air quality in small urban agglomerations in northwestern China and provide a reference for the application of policies. $\mathrm{PM}_{2.5}$ and $\mathrm{PM}_{10}$ concentrations in Pingliang were slightly higher than those in the other two cities due to the exhaust gas produced by coal processing, production and transportation. Qingyang, which is also positioned as an energy base, should learn from Pingliang, accelerate industrial upgrading and improve scientific and technological innovation capabilities to avoid deterioration of air quality due to energy mining, transportation and production.

\section{Acknowledgment:}

Funded by the Gansu Innovation Fund for Institutions of Higher Education (2020A-149) and (2020A-150).

\section{References:}

1. Lin X. Q., Wang D. 2016.Temporal and spatial evolution characteristics of urban air quality in China and its socio-economic driving forces [J]. Acta Geographica Sinica, 71(8): 1357-1371.

2. JACOB D J,WINNE R D A. Effect of climate change on air quality[J]. Atmospheric Environment, 2015,43(1):51-63.

3. Cui, M., Lu, H., Etyemezian, V., Su, Q., 2019. Quantifying the emission potentials of fugitive dust sources in Nanjing, East China.Atmospheric Environment, 207 (15), 129-135.

4. Li, C., Zhu, Z., 2018.Research and application of a novel hybrid air quality early-warning system: A case study in China.Science of The Total Environment, $626,1421-1438$.

5. Zheng, Q., Liu, H., Zhang, J., Chen, D., 2018.The effect of ambient particle matters on hospital admissions for cardiac arrhythmia: a multi-city casecrossover study in China. Environmental Health, $17(1), 60$.

6. HEI,2018.State of global air 2018: over 7 billion people face unsafe air.Special report.1-2.

7. Mu Q., Zhang S. Q.. Assessment of direct social and economic losses of large-scale smog incident in January 2013 in China [J]. China Environmental Science, 2013, 33(11): 2087-2094.

8. Liao Y. X., Peng C. Q., Yu S. Y. et al. Study on trend variation of air pollutants in Shenzhen from 2006 to 2016 [J]. Journal of Environmental Hygiene, 2017.7(6):439-444.

9. Ministry of Environmental Protection of the People's Republic of China, General Adminis-tration of Quality Supervision, Inspection and Quarantine of the People's Republic of China. Ambient air quality standard GB 3095-2012.[ S]. Beijing: China Environmental Science Press, 2012.

10. Geng F. H., Liu Q., Chen Y. H., Research progress of near-ground ozone. Desert and Oasis Meteorology, 2012; 6(6): 8-14.

11. Li S. C., Shi K, Liu C Q et al. Time-scale characteristics of the interaction between $\mathrm{NO} 2$ and $\mathrm{O} 3$ in summer: A case study in Hong Kong [J]. Environmental Chemistry, 2015,34(2):299-307.

12. Cheng N. L., Li Y. T., Zhang D W et al. Research on 
temporal and spatial distribution of $\mathrm{NO} 2$ in Beijing from 2013 to 2014 [J]. China Environmental Science, 2016, 36(1): 18-26.

13. Wang S. J., Xie S. Y., Wang J. X. et al. Analysis of urban air quality in Fenwei Plain from 2016 to 2019 [J]. China Environmental Monitoring, 2020, 36(6): 57-65.

14. Ma, X., Jia, H., 2016.Particulate matter and gaseous pollutions in three megacities over China: Situation and implication. Atmospheric Environment, 140, 476-494.

15. Sun R. G., Fan L., Feng X. B. et al. Temporal and spatial distribution characteristics of $\mathrm{PM}_{2.5}$ concentration in Ningxia Hui Autonomous Region in 2016 [J]. Earth and Environment, 2018, 46(4): 348354. 